PINWINKLER, Alexander, Wilhelm Winkler (1884-1984)

- eine Biographie. Zur Geschichte der Statistik und

Demographie in Österreich und Deutschland

\title{
Morgane Labbé
}

\section{OpenEdition}

Édition électronique

URL : http://journals.openedition.org/ifha/901

DOI : 10.4000/ifha.901

ISSN : 2198-8943

\section{Éditeur}

IFRA - Institut franco-allemand (sciences historiques et sociales)

\section{Référence électronique}

Morgane Labbé, «PINWINKLER, Alexander, Wilhelm Winkler (1884-1984) - eine Biographie. Zur Geschichte der Statistik und Demographie in Österreich und Deutschland ", Revue de l'IFHA [En ligne], Date de recension, mis en ligne le 01 janvier 2005, consulté le 22 septembre 2020. URL : http:// journals.openedition.org/ifha/901; DOI : https://doi.org/10.4000/ifha.901

Ce document a été généré automatiquement le 22 septembre 2020.

(CIFHA 


\title{
PINWINKLER, Alexander, Wilhelm Winkler (1884-1984) - eine Biographie. Zur Geschichte der Statistik und Demographie in Österreich und Deutschland
}

\author{
Morgane Labbé
}

Consacrer un travail de thèse de doctorat en histoire à la biographie d'un statisticien ne retient pas la première attention des non-spécialistes de cette discipline. Mais le paradoxe tient au fait que Wilhelm Winkler, figure marquante de la démographie autrichienne du XXe s., ne légua à la postérité aucune innovation théorique, alors que sa production scientifique, son engagement politique et ses activités institutionnelles furent considérables, et firent de lui le représentant, pendant plusieurs décennies, d'une discipline. Parce qu'il s'est efforcé tout au long de sa vie de construire en même temps sa carrière et la discipline dans laquelle il l'a menée, il constitue une figure exemplaire pour un travail biographique. Cet ouvrage vise à répondre à un autre enjeu : en Autriche comme en Allemagne, statistique de population et démographie ont été liées à partir des années 30 aux idéologies raciales, elles ont apporté leur contribution aux politiques eugéniques et d'extermination du régime nazi. Ces compromissions soulèvent des questions essentielles, auxquelles des travaux récents répondent progressivement, et cela au prix de révélations nécessaires sur le silence des milieux académiques sur leurs activités durant cette période, et sur le maintien après-guerre d'une grand part des personnels. La recherche d'A.P. s'inscrit explicitement dans ce contexte : Winkler a commencé sa carrière à la veille de la première guerre mondiale pour l'achever dans les années 1970, avec tous les honneurs de la corporation statisticienne. Certes, entre 1938 et 1945, il avait été congédié parce que sa femme était juive, mais pour cette raison, les récits hagiographiques l'ont présenté comme un résistant au régime, sans interroger ses engagements nationalistes et son soutien aux politiques familiales nazies. L'enquête scrupuleuse menée par A.P. soumet en revanche 
les activités de Winkler à une analyse sans complaisance, qui reste cependant attentive aux nuances qui permettent de saisir les basculements des revendications natalistes à l'eugénisme. En outre, durant la période de l'entre-deux-guerres, Winkler déploie ses activités de statisticien sur des terrains fortement politisés ; la Première Guerre mondiale et le démantèlement de l'Empire ont été pour sa génération la matrice d'une pensée nationaliste qui s'est radicalisée. Tout en restant en retrait des courants extrémistes, car plus proche du courant conservateur national autrichien, il deviendra néanmoins une autorité scientifique reconnue sur deux questions de cette actualité politique. Il s'agit d'une part de la question des minorités allemandes des nouveaux États d'Europe centrale, qui sont perçues dans l'opinion publique comme menacées et injustement victimes des Traités de Versailles et de Saint-Germain. À l'université de Vienne, il fonde et dirige un institut de statistique des minorités nationales, et veut s'appuyer sur la statistique comme sur un langage objectif pour la protection des minorités. Cette spécialisation, comme l'écrit justement A.P., lui donnera en Autriche et en Allemagne une notoriété publique, qui lui permettra alors de se distinguer de la communauté des statisticiens. C'est d'autre part la baisse de la natalité autrichienne, consécutive à la crise économique, qui constituera son autre spécialisation. Également perçue dans les catégories de la pensée du déclin des sociétés européennes, ce thème hante alors les imaginaires nationaux de tous les pays d'Europe. L'enjeu est aussi scientifique autour de la construction des indices de mesure du phénomène et la recherche des causes. Il se joue à l'échelle internationale, qui apporte en contrepartie la légitimité nécessaire auprès des gouvernements nationaux. Winkler comme ses homologues français, allemands ou italiens, cherche ainsi, par ses écrits et sa participation dans les rencontres internationales, à convaincre les décideurs politiques de la nécessité de la mise en place d'une législation nataliste. Si ces deux thèmes font de Winkler une personnalité publique, sur un troisième, l'enjeu est exclusivement académique. Très tôt Winkler cherche au moyen de ses travaux théoriques à introduire dans la statistique allemande et autrichienne, traditionnellement logico-empiriste, les formalisations mathématiques, qui sont en plein renouvellement avec les travaux des statisticiens anglo-saxons. Winkler, qui a une capacité remarquable à assimiler ces travaux mathématiques, alors qu'il n'a qu'une formation en droit, ambitionne ainsi de fonder la statistique comme une discipline autonome à l'université et d'obtenir une chaire de professeur. Mais son projet théorique est perçu par les autorités comme un défi lancé à la vieille école de statistique allemande, et sa réputation acquise dans l'espace public ne suffira pas contre sa marginalisation, accentuée sous le régime nazi. En revanche, au lendemain de la guerre, réhabilité et disposant toujours du capital intact constitué par ses engagements publics, il sera consacré comme la figure dirigeante de la statistique autrichienne, et pourra véritablement refaçonner la discipline et élargir ses instances. Il n'aura pourtant donné à ses ambitions théoriques aucune traduction méthodologique propre, restant un conciliateur entre deux écoles statistiques, plutôt qu'un fondateur.

2 A.P. a réalisé un travail impressionnant, qui repose sur l'exploitation exhaustive des archives et une lecture approfondie des travaux de Winkler. Il parvient à une reconstitution précise du contexte politique et académique, ainsi que de son environnement relationnel. Avec un tel ouvrage, l'histoire de la statistique, longtemps confinée à l'histoire des idées, répond enfin aux exigences d'une histoire sociale des sciences. 
3 Morgane LABBE (École des Hautes Études en Sciences Sociales, Paris) 